\title{
ELECTROCHEMICAL STUDIES AND EXTRACTION OF CHEMICAL AND ELECTROCHEMICAL PARAMETERS OF ZN(II) ION AT MERCURY ELECTRODE VIA CONVOLUTIVE VOLTAMMETRY AND DIGITAL SIMULATION METHODS
}

\author{
I. S. EL-HALLAG \\ Chemistry Department, Faculty of Science, Tanta University, Tanta, 31527, Egypt.
}

(Received: January 29, 2010 - Accepted: July 21, 2010)

\begin{abstract}
The electrochemical behaviour of $\mathrm{Zn}(\mathrm{II})$ ion as example of $\mathrm{C}_{\mathrm{rev}} \mathrm{E}_{\mathrm{irr}}$ system was studied at hanging mercury drop electrode in aqueous solution in the presence of $1 \mathrm{M} \mathrm{KCl}$ using cyclic voltammetry and convolutive voltammetry methods. Digital simulation technique was used to test the chemical and electrochemical parameters of $\mathrm{Zn}$ (II) ion estimated experimentally as well as verifying the proposed electrode mechanism.
\end{abstract}

Keywords: Electrochemical behaviour, $\mathrm{C}_{\mathrm{rev}} \mathrm{E}_{\text {irr }}$ system, cyclic voltammetry, convolutive Voltammetry, digital simulation.

\section{INTRODUCTION}

The electroreduction of $\mathrm{Zn}(\mathrm{II})$ has been extensively studied in aqueous and non-aqueous solutions and found to be controlled by both diffusion and charge transfer. ${ }^{1-6}$ At mercury electrode different mechanisms have been proposed for electrode reduction of metal cations, e.g., a simple electron transfer process 7,8 , stepwise electron transfer ${ }^{9}$, a CE or CEE mechanism. ${ }^{10,11}$ Several literature reports a possible validity of a mechanism involving two one-electron transfer has been discussed. ${ }^{12-14} \mathrm{The}$ electroreduction of $\mathrm{Zn}$ from $\mathrm{NaClO}_{4}$ solutions at a mercury electrode in the presence of tert-butanol is supposed to involve two consecutive one-electron transfer steps in the overall reaction. ${ }^{6}$

The kinetics of the electroreduction of zinc cations in non-aqueous solvents such as $\mathrm{DMF}^{15}$, $\mathrm{DMSO}^{16}$ and acetone ${ }^{17}$ were found to proceed as simple and two step processes.

Zinc is an essential element in the nutrition of animals and human. It acts as a cofactor in numerous enzymes and plays an important role in protein synthesis and cell division. It exerts a crucial influence on the maintenance of cell membrane stability and in the function of immune system. It also constitutes an active ingredient in medical products intended for topical application. Zinc salts are used in ophthalmic solutions, in lotions intended for treatment of chronic skin diseases and incorporated as astringents in various solutions. ${ }^{18}$ They range from impaired neuropsychological functions and wound healing to growth retardation, immune disorders and dermatitis. It is therefore, important to monitor the concentration of zinc and its salts in both biological materials and pharmaceutical formulations. ${ }^{19}$

Literature surveys of $\mathrm{Zn}$ (II) revealed the lack of convolutive voltammetry and digital simulation studies. In the present work, we have attempted to show how convolutive voltammetry and digital simulation method can be used to investigate the electroreduction mechanism of $\mathrm{Zn}$ (II) ion as an example of $\mathrm{C}$ E system in aqueous solution at hanging mercury drop electrode and also to evaluate the chemical and electrochemical parameters of the electrode process via new, simple and accurate method.

\section{EXPERIMENTAL}

Zinc sulphate (Merk, analytical grade) was used without further purification. Triple distilled water was used as solvent. The supporting electrolyte, potassium chloride, was analytical grade and was used as supplied (Fluka, analytical grade). Solutions of Zn (II) $\left(1 \times 10^{-4} \mathrm{M}\right)$ in triple distilled water, containing $1 \mathrm{M} \mathrm{KCl}$ as background electrolyte were selected. Working solutions were deoxygenated thoroughly with oxygen free nitrogen and a nitrogen atmosphere was maintained above the solution throughout the course of any experiment. The temperature was $298 \mathrm{~K}$.

Cyclic voltammetry and convoluted - deconvoluted voltammograms were performed on polarographic Analyzer Model 264 A (EG \& G, PAR) and the electrode assembly Model 303A, with a hanging mercury drop electrode (area $=2.61 \times 10^{-2} \mathrm{~cm}^{2}$ ) as a working electrode, $\mathrm{Ag} / \mathrm{AgCl}$ as a reference and $\mathrm{Pt}$ wire as a counter electrode. Digital simulation of the data for cyclic voltammetric experiments was carried out on an IBM computer via EG \& G Condesim package. The voltammetric data were stored in a magnetic floppy disk via a fast data- capture system through the interface which connects the computer with potentiostat. Cyclic voltammograms were recorded after background subtraction and iR compensation to minimize double-layer charging current and solution resistance. Cyclic voltammetric data were studied at scan rates ranging from 0.05 to $5 \mathrm{Vs}^{-1}$.

\section{RESULTS AND DISCUSSION}

\section{Cyclic voltammetry}

Figure 1A shows a cyclic voltammogram of $\mathrm{Zn}$ (II) ion recorded at $v=0.05$ $\mathrm{Vs}^{-1}$ and $\mathrm{T}=298 \mathrm{~K}$ on a hanging mercury drop electrode in $1 \mathrm{M} \mathrm{KCl}$ solution. There are reduction and oxidation peaks in agreement with the slow nature of electron transfer process. From the voltammograms it can be seen that, there is a difference between $E_{1 / 2}$ and $E_{p c}$ in the range of $142-527 \pm 2 \mathrm{mV}$ at various scan rates, i.e. a value much different than the $14 \mathrm{mV}$ expected for a simple reversible two - electron process. ${ }^{20}$ Figure 1B shows the effect of sweep rate on the variation of $E_{12}-E$ values and on the peak potential separations of the some recorded cyclic voltammograms. This behaviour indicates that, the values of $\left(\mathrm{E}_{\mathrm{pc}}-\mathrm{E}_{\mathrm{p}}\right)$ and $\left(\mathrm{E}_{\mathrm{pc}}-\mathrm{E}_{\mathrm{p} / 2 / 2}\right)$ for $\mathrm{Zn}(\mathrm{II}) / \mathrm{Zn}(\mathrm{Hg})$ system deviate largely from $29.5 \mathrm{mV}$ as estimated for a simple reversible two-electron system which can be attributed to the slow charge transfer process associated with amalgam formation process.

\section{Figure 1A}

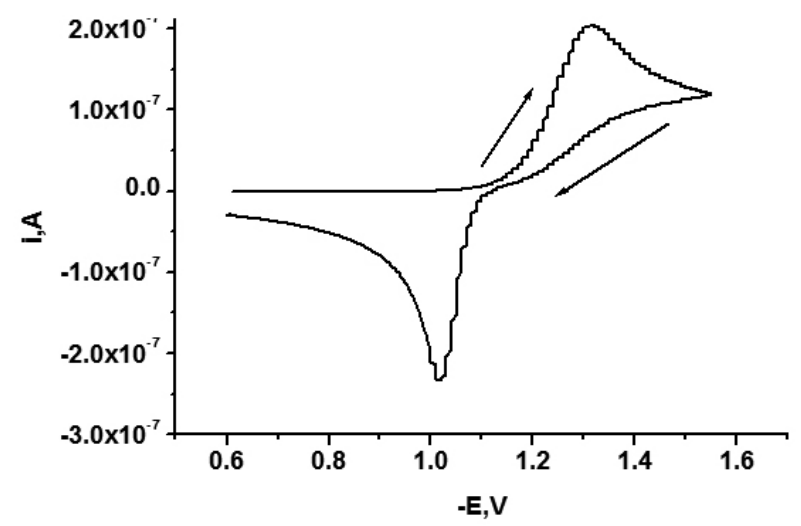




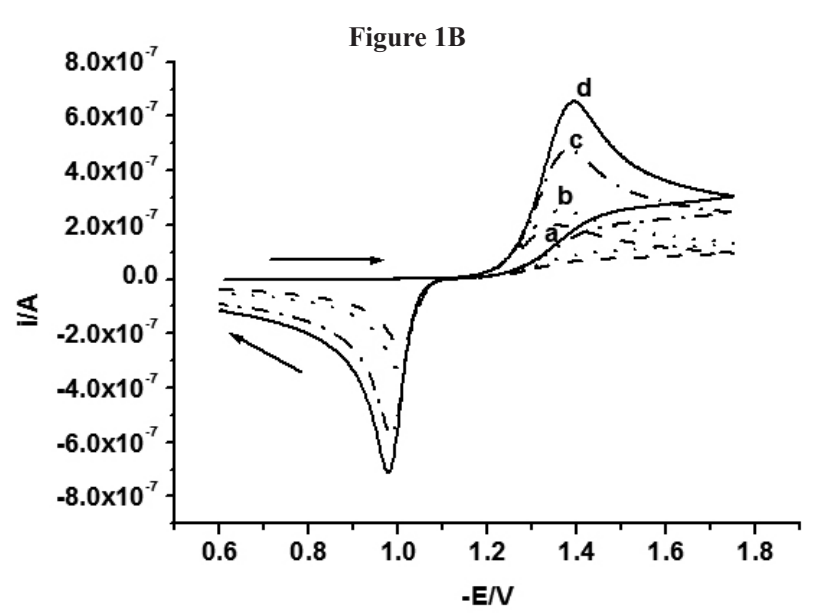

Figure 1: (A) Cyclic voltammogram of $\mathrm{Zn}(\mathrm{II})$ ion in $1 \mathrm{M} \mathrm{KCl}$ solution, $\mathrm{v}=$ $0.05 \mathrm{Vs}^{-1}$ and (B) cyclic. voltammograms of $\mathrm{Zn}(\mathrm{II})$ at different scan rates (a) $\mathrm{v}$ $=0.05$, (b) $\mathrm{v}=0.1$, (c) $\mathrm{v}=0.2$ and (d) $\mathrm{v}=1 \mathrm{Vs}^{-1}$ and $\mathrm{T}=298 \mathrm{~K}$.

In slow charge transfer process the standard heterogeneous rate constant, $\mathrm{k}_{\mathrm{s}}$, was calculated according to the following equation: ${ }^{21}$

$$
k_{s}=2.18\left(\frac{D \alpha n F v}{R T}\right) \quad \exp \left[-\frac{\alpha^{2} n F}{R T}\left(E_{p c}-E_{p a}\right)\right.
$$

The diffusion coefficient, $D$, of the $\mathrm{Zn}$ (II) ion was calculated according to the method established by Nicholson and Shain. ${ }^{22}$ The half-wave potential $\left(E_{12}\right)$ of the investigated system was determined from the voltammogram as the mean positions of the peak potentials, ie. $\left(E_{p c}+E_{p d}\right) / 2$. The calculated values of $k_{s}, D$ and $E_{1 / 2}$ are given in Table 1 . The value of the transfer coefficient, $\alpha$, for the cathodic reduction of the $\mathrm{Zn}$ (II) ion, calculated from the relationship ${ }^{23}$ $\left(E_{p c}-E_{p c / 2}\right)=48 / \alpha_{\mathfrak{a}}$, was reported in Table 1 .

Table 1: Electrochemical parameters of $\mathrm{Zn}(\mathrm{II})$ ion in $1 \mathrm{M} \mathrm{KCl}$ and $298 \mathrm{~K}$

\begin{tabular}{|c|lcc|}
\hline Parameters & \multicolumn{3}{|c|}{ Techniques } \\
& $\mathrm{Cv}$ & Conv & decon \\
\hline $\mathrm{k}_{\mathrm{s}} \times 10^{7}$ & 2.8 & 2.6 & - \\
$\mathrm{m} / \mathrm{s}$ & & & \\
$\alpha$ & 0.31 & --- & 0.27 \\
$-\mathrm{E}_{1 / 2}, \mathrm{~V}$ & 1.111 & -- & 1.114 \\
& & & \\
$\mathrm{Dx}_{10}$ & 2.44 & 2.51 & 2.47 \\
$\mathrm{~m}^{2} / \mathrm{s}$ & & & \\
\hline
\end{tabular}

CV (Cyclic voltammetry), Conv (Convoluted voltammograms), decon (deconvoluted voltammogram).

It was found that, the values of cathodic peak potential, $E_{p c}$ shift towards more cathodic values, with increasing the sweep rate, also, the peak separation $\left(\Delta E_{p}\right)$ values increase with increasing the sweep rate. It was noted that, the values of $i p f / v^{1 / 2}$ decrease as $v$ increase, and $i / i$ increase with $v$ and is always greater than unity confirmig the $C E$ behaviour of the electrode reaction of $\mathrm{Zn}$ (II) ion $^{23}$.

Convolutive voltammetry

It was found that convolution-deconvolution voltammograms was used as a valuable and simple tool for elucidation the complicated electrode mechanism as well as the determination of the accurate electrochemical parameters. ${ }^{24-27}$ The shape of the $I_{I}-E$ curve exhibit important feature for the identification of the nature of the electrode process. For a simple rapid charge transfer, the shape of
$I_{1}-E$ curve is identical to the $i-E$ polarogram at a dropping mercury electrode. ${ }^{28,29}$ For quasi-reversible and slow charge transfer there is a separation between the forward and backward direction of the $I_{l}$ convolution, whereas in the case of a chemical reaction following the charge transfer, i.e. EC mechanism, the backward direction of $I_{l}$ convolution does not return to the initial value. ${ }^{30} \mathrm{On}$ the other hand, in case of a reversible chemical reaction preceeding charge transfer, i.e. $C E$ mechanism, the limiting convoluting current $I_{\text {lim }}$ does not produce the plateau value at low scan rate, Fig. $2 \mathrm{~A}$, while at high scan rate the limiting convoluting current $I_{\text {lim }}$ gives the plateau value Fig.2B. ${ }^{26}$
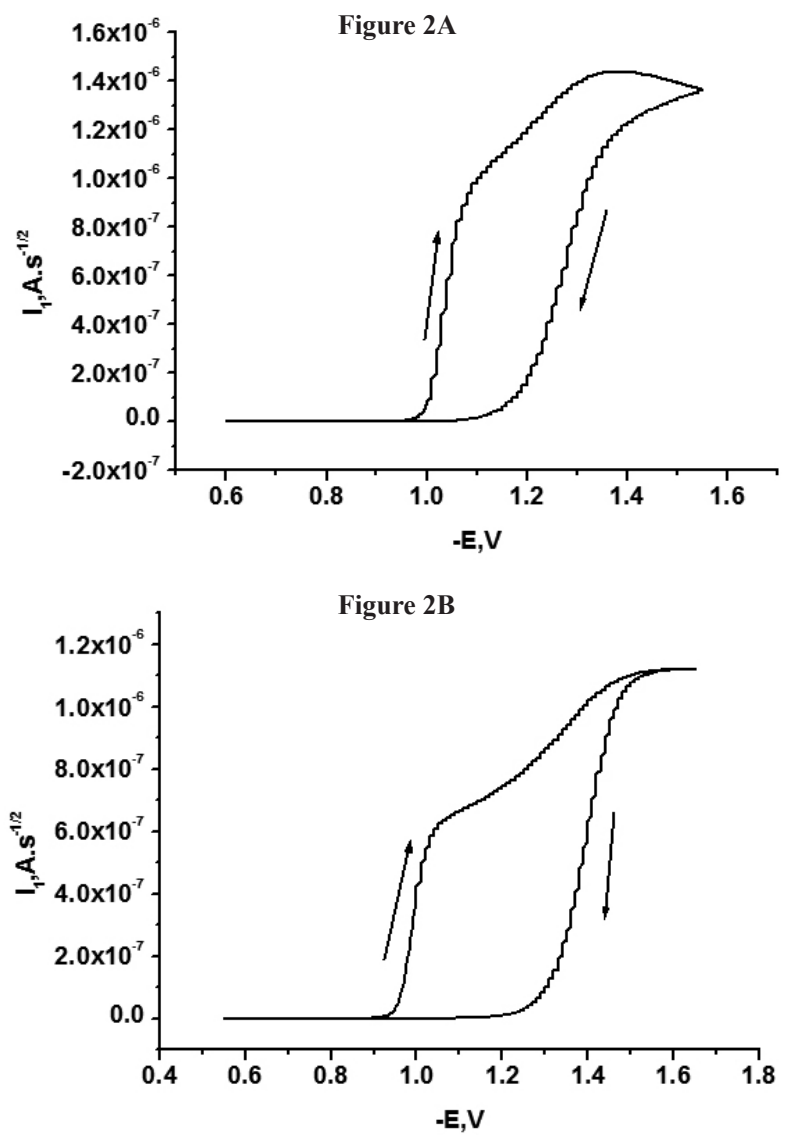
(B).

Figure 2: $\mathrm{I}_{1}$ convolution of $\mathrm{Zn}(\mathrm{II})$ ion at $\mathrm{v}=0.05 \mathrm{~V} / \mathrm{s}(\mathrm{A})$ and $\mathrm{v}=2 \mathrm{Vs}^{-1}$

The convolution of the current data with an inverse square root of time, $I_{l}$ is defined as: $24-30$

$$
I_{1}=(1 / \sqrt{ } \pi) \int_{0}^{t} \frac{i(u)}{\sqrt{ }(t-u)} d u
$$

where $I_{l}$ is the convoluted current at the total elapsed time and i(u) is the experimental current at time $u$.

For the following $C E$ scheme in term of an electrochemical reduction mechanism

$$
X \stackrel{k_{1}}{\stackrel{k_{-1}}{\rightleftharpoons}} \quad Y+n e \quad \underset{\substack{k_{b, h} D, a \\ k_{f, h}>>k_{b, h}}}{\stackrel{k_{f, h}, E^{o}}{\rightleftharpoons}} Z
$$

$K=k_{1} / k_{-1}\left(k_{c}=k_{1}+k_{-1}\right)$ 
the limit of $I_{1}$ as $E$ approaches infinity at high scan rate is known as the limiting convoluting current $\left(I_{\text {lim }}\right)$ and is defined as: ${ }^{30}$

$$
I_{\text {lim }}=n F S C_{Y}^{b} \sqrt{ } D
$$

where $\mathrm{n}$ is the number of electrons consumed in electrode reaction, $\mathrm{F}$ is the Faraday constant, $\mathrm{S}$ is the electrode surface area and the remaining terms have their usual definitions. This relation is quite useful for the evaluation of the diffusion coefficient of the electroactive species via $C y^{b}$ and vice - versa, irrespective of the rate of charge transfer. Value of the diffusion coefficient estimated via Eq. (4) is listed in Table 1.

In the present work we will use the kinetic convolution, $I_{2}$, for calculating the homogeneous chemical rate constant,$k c$, equilibrium constant, $K$, and half-wave potential, $E_{1 / 2}$, of $C E$ system which is defined as: ${ }^{29,30}$

$$
I_{2}=(1 / \sqrt{ } \pi) \int_{0}^{t} \frac{i(u) \exp \{-k c(t-u)\} d u}{\sqrt{ }(t-u)}
$$

The kinetic convolution, $\mathrm{I}_{2}$, is similar to the semiintegral except that the current data are not convolved with just a different term (i.e., $1 / \mathrm{N} t$ ) but also a kinetic expression (i.e., $\exp (-k t)$. The kinetic convolution, $I_{2}$, is a function with a value proportional to the concentration of species $Y$ at the electrode (i.e., $C y(0, t)$.

Deconvoluted voltammogram $\left(d I_{l} / d t v s . E\right)$ is used as a precise method for calculating $E_{1 / 2}$ by using transformation of the current rather than the actual current values. ${ }^{30-32}$ In the case of fast charge transfer, $d I_{I} / d t$ gives two mirror - image peaks with maximum amplitude at $E_{J / 2}$ and half-width of (2RT) $n F) \ln ((\sqrt{ } 2+1))(\sqrt{ } 2-1)) m V$, i.e $3.526 R T / n F$ i.e $90.53 / n m V$ at $298 \mathrm{~K}$. In case of slow charge transfer, the average value of the forward and backward peak potentials equals approximately to $E_{12}$. Fig.3 indicates an example of deconvoluted voltammogram at $0.1 \mathrm{VS}^{-1}$. It was found that the ratio of the forward to backward sweep $(d I / d t) /(d I / d t)$, of deconvolution increases with increasing the scan rate. Table 2 includes the numerical values of $\left(d I_{l} / d t\right)_{f} /$ $(d I / d t)_{b}$ at various scan rate. The $E_{12}$ values of the investigated system was calculated from deconvoluted voltammograms was listed in Table 1. The half - peak width of the deconvoluted voltammograms, $W^{P}$, was found to be in the range of $0.148-0.296 V$ confirming the slow nature of electrode process. The variation of $W^{P}$ with scan rate was listed in Table 2.

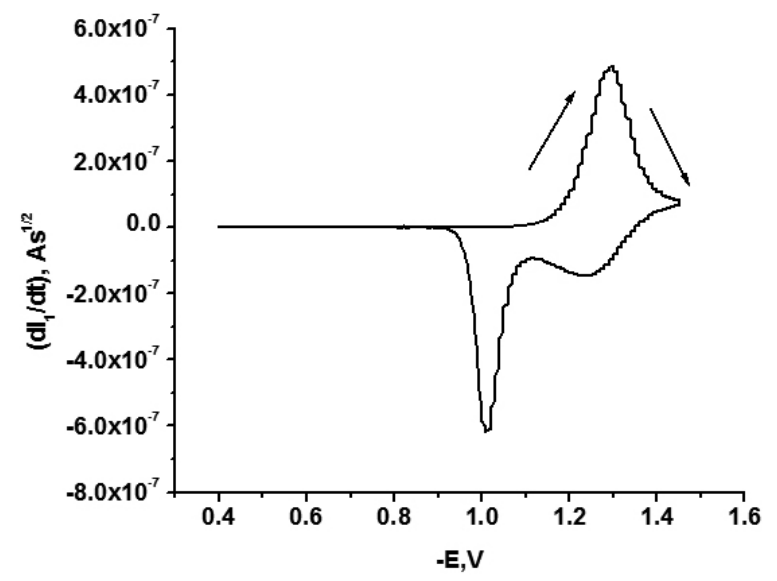

Figure 3: Deconvoluted voltammogram of $\mathrm{Zn}(\mathrm{II})$ ion at $\mathrm{v}=0.1$ Vs-1.
Table 2: Values of peak characteristics extracted from convoluted deconvoluted voltammograms at various values of scan rate.

\begin{tabular}{|c|lcc|}
\hline$v, V \cdot s^{-1}$ & $W^{P}, V$ & $\left(d I_{l} / d t\right)_{f} /\left(d I_{l} / d t\right)_{b}$ & $I_{l h} A . s^{-1 / 2}$ \\
\hline 0.05 & 0.148 & 0.850 & $3.3 \times 10^{-7}$ \\
0.10 & 0.174 & 0.950 & $3.2 \times 10^{-7}$ \\
0.20 & 0.183 & 1.150 & $2.8 \times 10^{-7}$ \\
0.50 & 0.232 & 1.270 & $9.1 \times 10^{-9}$ \\
1.00 & 0.241 & 1.430 & $6.9 \times 10^{-9}$ \\
2.00 & 0.265 & 1.450 & $4.0 \times 10^{-9}$ \\
5.00 & 0.296 & 1.490 & $3.6 \times 10^{-9}$ \\
\hline
\end{tabular}

The transfer coefficient, $\alpha$, in this work was calculated from the relationship $W^{P}=2.94 R T / \alpha n F=75.5 / \alpha n ~ m V$ for the slow charge transfer at $298 \mathrm{~K}$. The calculated value of $\alpha$ via deconvoluted voltammogram is found to be $0.27 \pm$ 0.03 which agrees well with those calculated from $C V$ experiments.

Fig. 4 shows the presentation of $I_{l}$ convolution at the end of the first half scan $I_{H}$, and the ratio of the forward to backward scan of deconvoluted voltammograms, $\left(d I_{l} / d t\right)_{f} /\left(d I_{l} / d t\right)_{b}$ versus the scan rate $v$. From inspection of Fig.4 it was noted that $I_{t}$ decreases with increasing $v$ and $\left(d I_{t} / d t\right)_{f} /(d I / d t)$ increases with increasing $v$ i.e both plots exhibit two curves mirror image. This behaviour gives strong evidence of the $C_{r e v} E_{i r r}$ nature of $Z n(I I)$ ion in aqueous media at $H M D E .{ }^{26}$
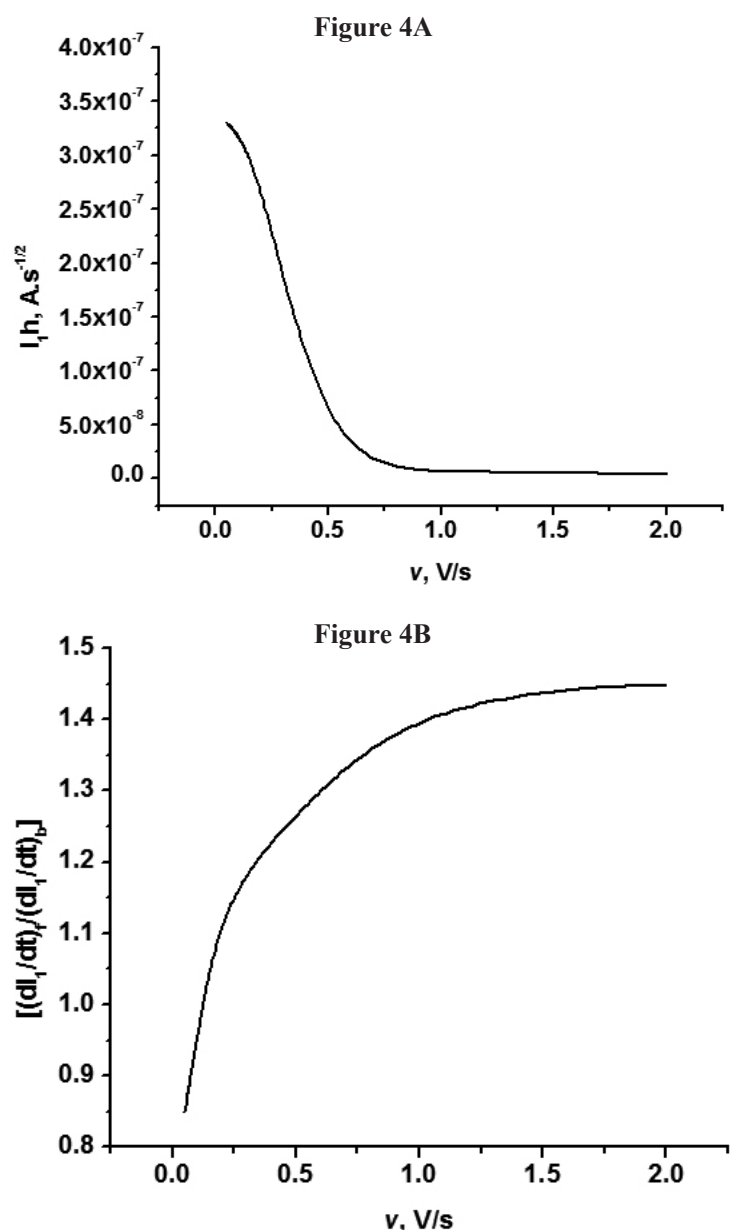

Figure 4: $I_{1}$ convolution at the end of the first half scan, $I_{1 b}$, (A), and the ratio of the height of the forward scan of deconvoluted current to the backward one $\left[\left(\mathrm{dI}_{1} / \mathrm{dt}_{\mathrm{f}} /\left(\mathrm{dI}_{1} / \mathrm{dt}\right)_{\mathrm{b}}\right](\mathrm{B})\right.$ vs $\mathrm{v}$ of $\mathrm{Zn}(\mathrm{II})$ ion. 
Extraction of $k_{c}, K$ and $E_{l / 2}$

For the $C E$ reaction described in $E q$. (3) the following equation was verified: ${ }^{26}$

$$
\frac{I_{1}(\sqrt{ } D)}{k_{f, h} e^{-\alpha_{\zeta}}}=I_{l i m}-\frac{K I_{1}}{1+K}-\frac{I_{2}}{1+K}-\left(I_{l i m}+I_{1}\right) e^{\zeta}
$$

where $k_{f, h}$ is the forward heterogeneous rate constant, $\zeta=n F / R T\left(E-E_{1 / 2}\right)$ is the 'reduced' potential, and the other terms have their usual definition. At potential well 'past' the wave, Eq. (6) takes the following form:

$$
I_{\text {lim }}=\frac{K I_{1}}{1+K}+\frac{I_{2}}{1+K}
$$

The true value of $k_{c}$ can be evaluated by inserting various values of test chemical rate constant until the $I_{2}$ convolution returns to the initial value similar to $I$, convolution. This means that, the $\mathrm{k}$ value is established at the point when $I_{2}$ convolution is identical exactly to $I_{1}$ convolution. The establishment of the correct value of $k_{c}$ via $I_{2}$ convolution is illustrated in Fig.5.
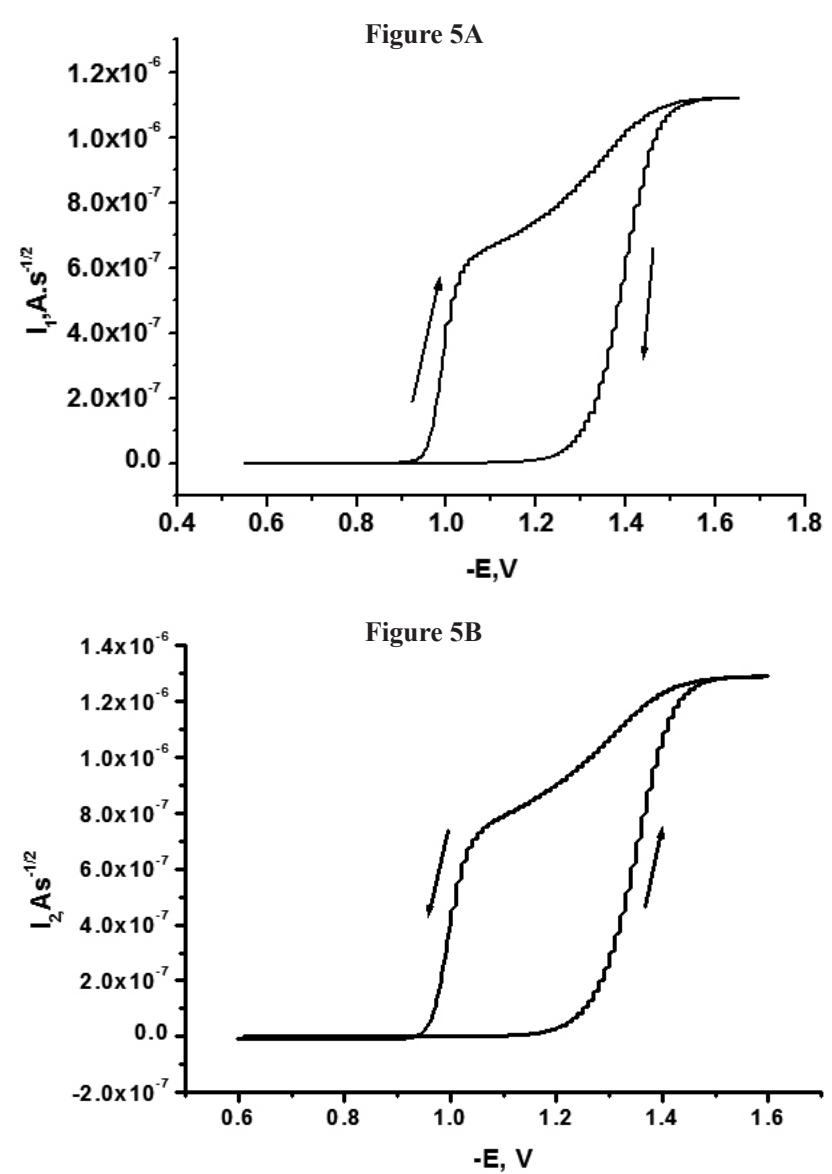

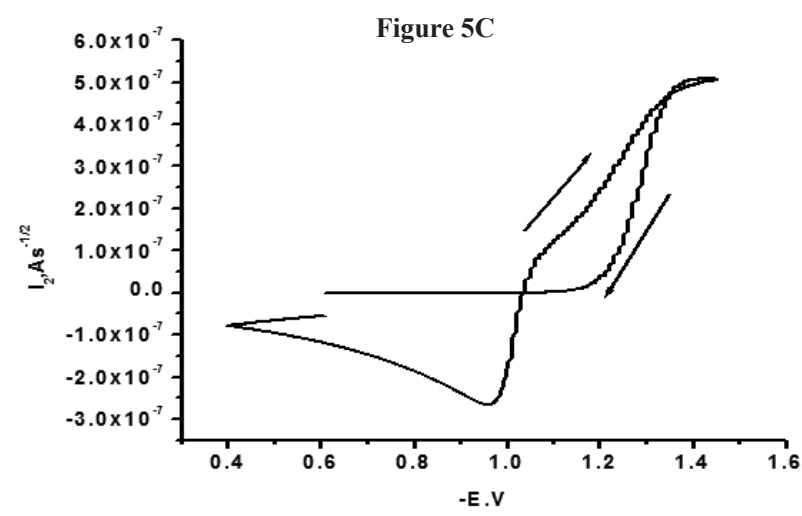

Figure 5: Estimation of the corrected value for the homogeneous rate constant via comparison between $I_{1}$ and $I_{2}$ convolution of $\mathrm{Zn}$ (II) ion at high scan scan speed $2 \mathrm{Vs}_{1}$. (A) $\mathrm{I}_{1}$. convolution, (B) $\mathrm{I}_{2}$ convolution at true $\mathrm{k}_{\mathrm{c}}=0.02$ $\mathrm{s}^{-1}$ and $(\mathrm{C}) \mathrm{I}_{2}$ convolution at high $\mathrm{k}_{\mathrm{c}}=0.4 \mathrm{~s}^{-1}$.

It was proved that, for $C E$ scheme, at the end of the first scan, i.e. well past the wave at low and high scan rates, $K>>1$, i.e. $1+\mathrm{K} \approx \mathrm{K}$, and $E q$. (7) give the following form: ${ }^{26,27}$

$$
\begin{array}{ll}
\text { i.e. } \quad & I_{\text {lim }}-I_{1}-\left(I_{2} / K\right)=0.0 \\
K\left(I_{\text {lim }}-I_{1}\right)=I_{2}
\end{array}
$$

This means that $E q$. (9) is used to calculate $E$ and $k$ (true) simultaneously for $k_{c}$ (test) values from the plot of $I_{\text {lim }}-I_{1}, I_{2}$ versus $E$. This procedure is illustrated in Fig.6 for experimental data of $Z n(\mathrm{II})$ ion which proceeds as $C_{r e v} E_{i r r}$ mechanism at scan rate $2 \mathrm{~V} / \mathrm{s}$. Also, at $I_{1}$ and $I_{2}$ values corresponding to $E_{1 / 2}^{\text {rev }}$ value the following is verified:26

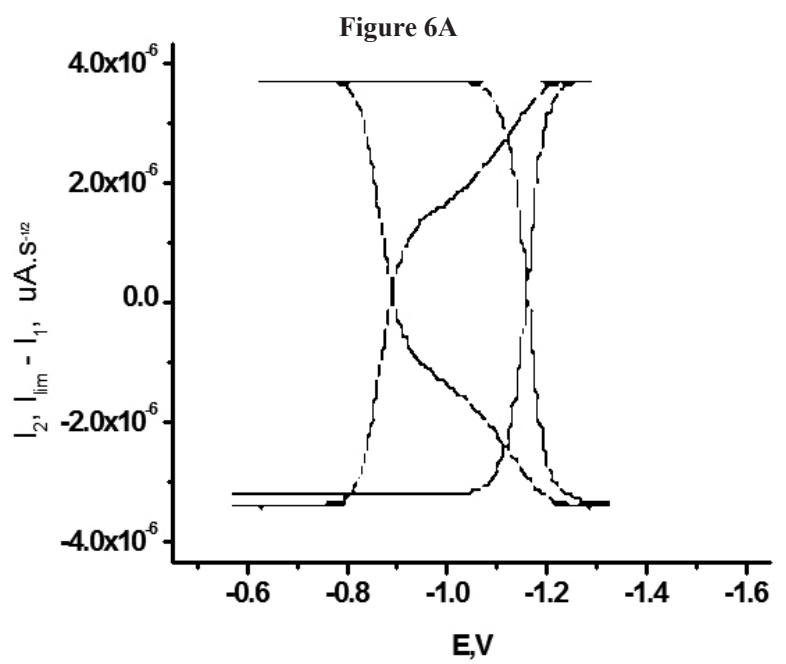




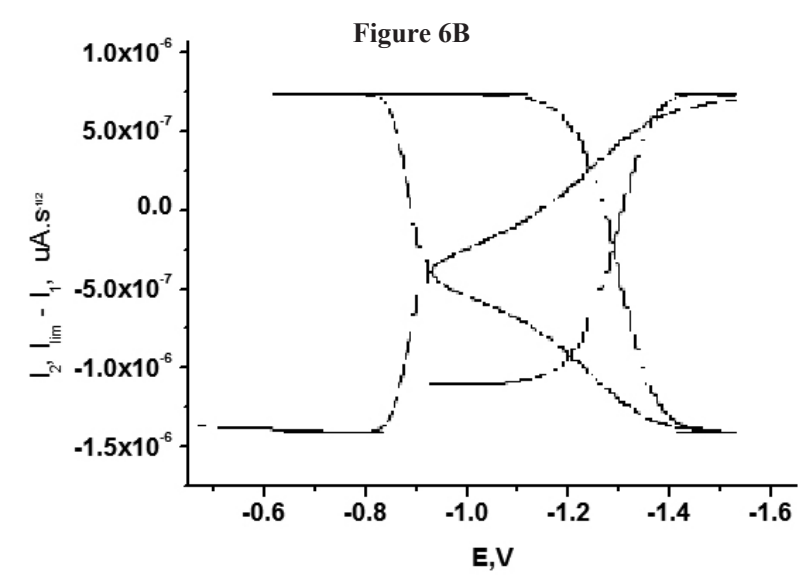

Figure 6: $\mathrm{I}_{\lim }-\mathrm{I}_{1}$ and $\mathrm{I}_{1}$ vs $\mathrm{E}$ of $\mathrm{Zn}$ (II) ion, (A) at true value of $\mathrm{kc}$ and (B) at high value of $\mathrm{kc}$.

$$
K=\quad \frac{I_{2}\left(E_{1 / 2}\right)}{I_{I}\left(E_{1 / 2}\right)}
$$

The values of $k_{c}, K, I_{1}\left(E_{1 / 2}\right)$ and $I_{2}\left(E_{1 / 2}\right)$ were listed in Table 3, which confirm the accuracy as well as the simplicity of this method for calculation of the values of $k_{c}$ and $K$ of the $C E$ system at slow rate of charge transfer at potential corresponding to $E_{1 / 2}$ via $E q$. (10). The value of $E_{1 / 2}(-1.11 V)$ calculated from the intersection point between $\left(I_{2}, I_{\text {lim }}-I_{1}\right.$ vs $E$ was found to agree well with that determined from cyclic voltammetry and deconvoluted voltammograms.

Table 3: Values of $\mathrm{k}_{\mathrm{c}}, \mathrm{I}_{1}\left(\mathrm{E}_{1 / 2}\right), \mathrm{I} 2\left(\mathrm{E}_{1 / 2}\right)$ and $\mathrm{K}$ of $\mathrm{Zn}(\mathrm{II})$ ion at scan rate $5 \mathrm{~V} / \mathrm{s}$

\begin{tabular}{|l|lcl|}
\hline$k_{c} s^{-1}$ & $I_{1}\left(E_{1 / 2}\right) \times 10^{7}$ & $I_{2}\left(E_{1 / 2}\right) \times 10^{7}$ & $K$ \\
& $\left(A s^{-1 / 2}\right)$ & $\left(A s^{-1 / 2}\right)$ & \\
\hline 0.02 & 3.055 & 3.0336 & 0.993 \\
0.20 & & 2.9023 & 0.949 \\
2.00 & & 2.6655 & 0.872 \\
\hline
\end{tabular}

In the present communication it was found that convolutive voltammetry was used as accurate method for determination of the rate of conversion of the electroinactive species $(X)$ to electro-active species $(Y)$. Also, the plot of $I_{l h}$ and $\left(d I_{I} / d t\right)_{f} /\left(d I_{I} / d t\right)_{b} v s v$ is considered as a simple and new route for knowing the type of electrode mechanism.

Determination of $D$ and $n$

It was indicated that, at high sweep rates $\mathrm{I}_{1} \mathrm{I}_{\lim }$ "past" the wave thus $\mathrm{I}_{\lim }$ gives the value of $D$ irrespective of $k_{c}$ and $k_{s}$ values. Also from $E q$. (11) the diffusion coefficient can be calculated from deduced limiting convoluted current $\left(I_{\text {lind }}\right)^{22,26}$

$$
I_{\text {limd }}=\frac{I_{1} I_{\text {lim }}}{3.099 \sqrt{\alpha n_{a} v}}
$$

where $i_{\mathrm{p}}$ is the peak current of the irreversible cyclic voltammogram, and $I_{\text {limd }}$ is the deduced limiting convoluted current, the other terms have their usual definition. The value of diffusion coefficient $(D)$ evaluated from $I_{\text {lim }}$ (Eq. 4) and $I_{\text {limd }}$ (Eq. 11) are reported in Table 4 at various values of scan rate. The estimated value of $D$ via $E q$. (11) indicates the importance of this method for calculating the diffusion coefficient without performing a convolution procedure.
Table 4: Values of $I_{\text {lim }}, I_{\text {limd }}$, and diffusion coefficient of $\mathrm{Zn}(\mathrm{II})$ ion

\begin{tabular}{|c|c|c|c|c|c|c|c|}
\hline \multirow[t]{2}{*}{$v, \mathrm{Vs}^{-1}$} & \multirow[t]{2}{*}{$\begin{array}{r}\mathrm{I}_{\mathrm{lim}} \times 10^{7} \\
\left(\mathrm{As}^{-1 / 2}\right)\end{array}$} & \multirow[t]{2}{*}{$\begin{array}{l}\mathrm{I}_{\text {limd }} \mathrm{x} 10 \\
\left(\mathrm{As}^{-1 / 2}\right)\end{array}$} & \multicolumn{3}{|c|}{$\begin{array}{l}\mathrm{Dx} 10^{9} \\
\left(\mathrm{~m}^{2} / \mathrm{s}\right)\end{array}$} & \multirow[t]{2}{*}{$\left(d I_{l} / d t\right)_{f}$} & \multirow[t]{2}{*}{$\mathrm{n}$} \\
\hline & & & a & $\mathrm{b}$ & c & & \\
\hline 1.0 & 2.80 & 2.70 & 2.57 & 2.39 & 2.50 & 2.51 & 2.11 \\
\hline 2.0 & 2.68 & 2.60 & 2.36 & 2.22 & 2.50 & 3.40 & 1.90 \\
\hline 5.0 & 2.75 & 2.71 & 2.48 & 2.41 & 2.50 & 3.70 & 1.88 \\
\hline
\end{tabular}
estimated from $\mathrm{I}_{\lim }$ and $\mathrm{I}_{\text {lim}}$.

(a) Values of D determined from deduced $\mathrm{Il}_{\mathrm{im}}$ via Eq. (4),

(b) values of $\mathrm{D}$ determined from $\mathrm{I}_{\text {limd }}$ via Eq.(11) and

(c) values of $\mathrm{D}$ used in simulation.

The number of electrons, $\mathrm{n}$, participating in the electroreduction of $Z n(I I)$ ion was determined via the following equation: ${ }^{26}$

$$
n=\frac{\left(d I_{l} / d t\right)_{\mathrm{f}}}{11.5666 I_{\text {lim }} v \alpha}
$$

where $\left(d I_{I} / d t\right) f=\alpha n^{2} F^{2} S C D^{1 / 2} v / 3.3674 R T, I_{\text {lim }}$ is the limiting convoluted current and the other terms have their usual definitions. The values of $n$ and $(d I / d t) f$ at various scan rate are listed in Table 4. It was found that, the number of electrons involved in the electrode reaction is $1.98 \pm 0.03 \approx 2.0$.

Determination of $k$

In case of slow charge transfer which follows reversible chemical process i.e, $C_{r e v} E_{i r r}$ scheme, the standard heterogeneous rate constant, $k_{s}$ can be calculated from convoluted voltammogram according to the following relationship: ${ }^{28}$

$$
E=E^{0}+\frac{R T}{\alpha n F} \ln \left[\frac{k_{s}\left(I_{\text {lim }}-I_{I}\right)}{i \sqrt{ } D}\right]
$$

It was found that the calculated values of $\mathrm{k}_{\mathrm{s}}\left(2.5 \times 10^{-7} \mathrm{~m} / \mathrm{s}\right)$ via $E q$. (13) compare well with those calculated from cyclic voltammetric experiments.

\section{Digital simulation}

Digital simulation of data for cyclic voltammetric experiments was carried out via $E G \& G$ Condesim Package for determination of the accurate values of the electrochemical parameters. The direct method of the evaluation of the parameters was made by matching of the theoretical voltammograms on the experimental data, using the average experimentally determined parameters. Fig. 7 shows the good agreement between the experimental and generated voltammograms of the $C_{r e v} E_{\text {irr }}$ system at scan rate $0.05 \mathrm{VS}^{-1}$ confirming the accuracy of the determined electrochemical parameters

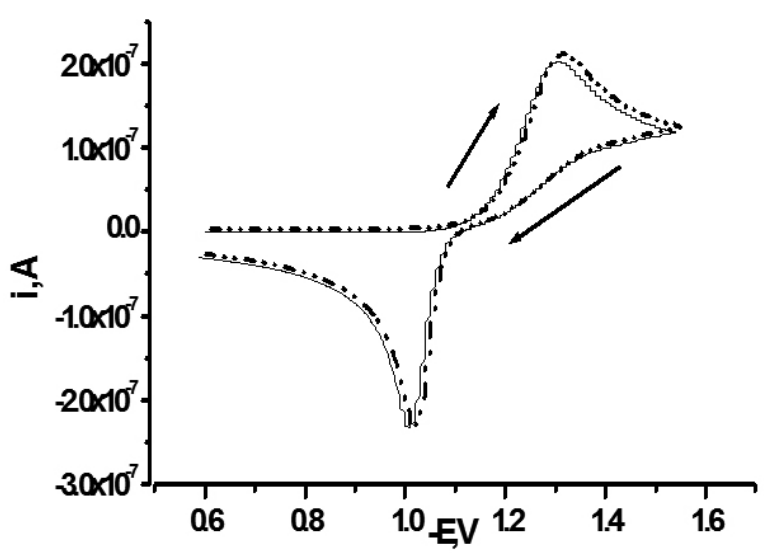

Figure 7: Voltammograms of $\mathrm{Zn}(\mathrm{II})$ ion -----: experimental, ........ simulated; sweep rate: $0.05 \mathrm{Vs}-1, \mathrm{~T}=298 \mathrm{~K}$. 
In this article the most accurate test for evaluating the type of electrode reaction for the reduction of $Z n(I I)$ was done by performing simulation with the following type of electrochemical reactions:

i- $E E$ mechanism, where the potential difference between $E^{0}{ }_{1}$ and $E^{0}{ }_{2}$ produce a single wave,

ii- $E$ mechanism, where $n$ is equal to $1 \& 2$

iii- $C E$ mechanism, where $n$ is equal to 1 and

iv- $C E$ mechanism, where $n$ is equal to 2 .

Figure 8 shows the comparison between the theoretical voltammograms of the three electrochemical reactions (types i - iii) vs the experimental cyclic voltammogram of $\mathrm{Zn}(\mathrm{II})$ ion at $v 0.05 \mathrm{Vs}^{-1}$ indicating large deviation between the selected three simulated types with the experimental $\mathrm{Zn}$ (II) ion and confirming the accuracy of the suggested mechanism of electroreduction of $\mathrm{Zn}$ (II) ion in aqueous solution at $298 \mathrm{~K}$.
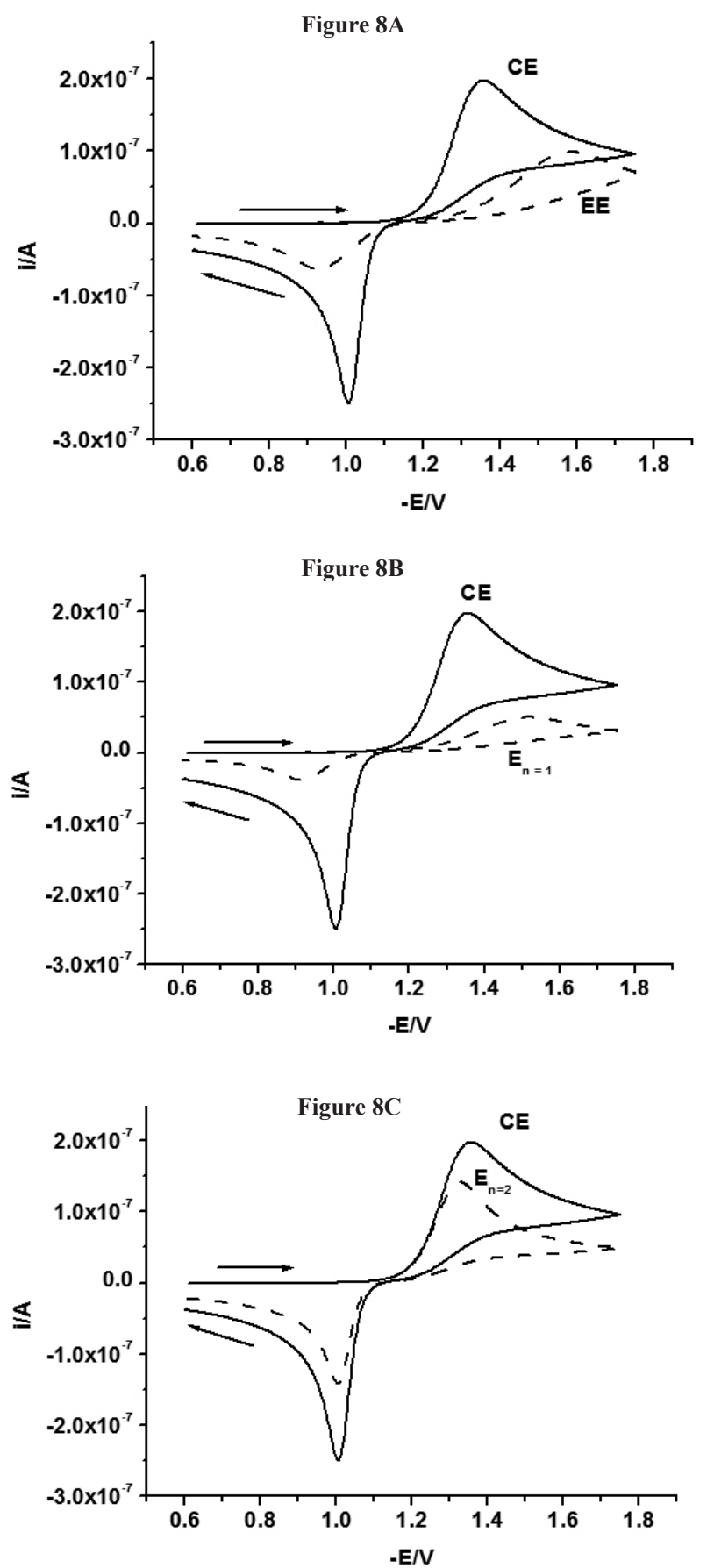

Figure 8D

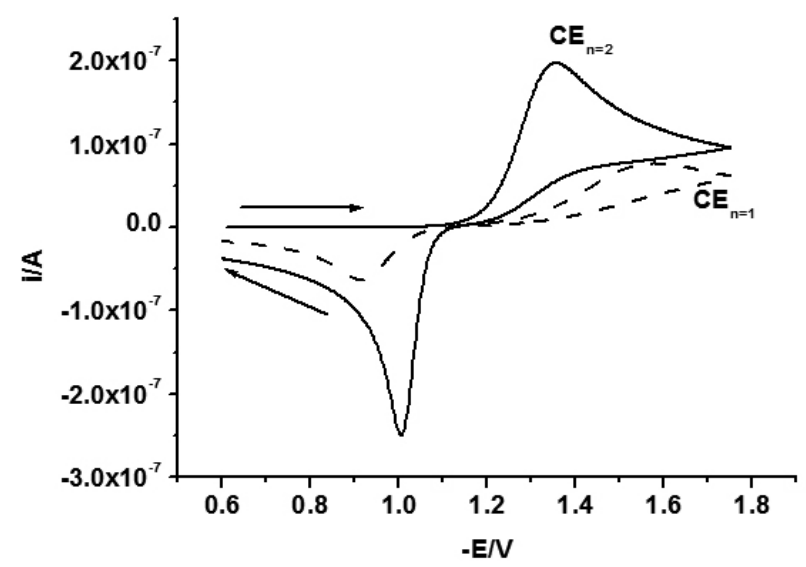

Figure 8: Experimental cyclic voltammogram of $\mathrm{Zn}(\mathrm{II})$ ion at sweep rate of $0.05 \mathrm{Vs}^{-1}$ versus the following simulated cyclic voltammograms (A) EE system, (B)simulated $\mathrm{E}$ system where $\mathrm{n}=1$, (C) simulated $\mathrm{E}$ system where $\mathrm{n}=$ 2 and (D) simulated CE system where $\mathrm{n}=1$.

The electrochemical parameters used in generating the simulated cyclic voltammograms is the experimental electrochemical parameters. From the measured peak separation $\Delta E_{p}, i_{p}, E_{p}$, and $E_{p}-E_{p / 2}$ of the voltammogram, and $W^{P}$ and $\left(d I_{I} / d t\right)_{f} /(d I / d t)$ of the deconvoluted voltammogram, the nature of electrode reaction of $\operatorname{Zn}(I I)$ ion in aqueous solution is predicted. Table 5 shows the measured values of peak characteristic of cyclic and convolutive voltammetry. It was found that, the theoretical peak characteristics of the type iv ( $C E$ mechanism) agrees well with the experimental peak characteristics which indicates that the electrochemical reaction of $Z n(I I)$ ion in aqueous solution containing $1 M \mathrm{KCl}$ at a mercury electrode proceeds as $C_{r e v} E_{j u \mathrm{r}}$ as follows:

Table 5: Peak characteristics of cyclic and convolutive voltammetry at different types of simulated cyclic voltammograms and $\mathrm{v}=0.5 \mathrm{~V} / \mathrm{s}^{-1}$.

\begin{tabular}{|c|c|c|c|c|c|}
\hline $\begin{array}{l}\text { Electrode } \\
\text { reaction }\end{array}$ & $\begin{array}{l}\Delta \mathrm{E}_{\mathrm{p}} \\
\mathrm{V}\end{array}$ & $\begin{array}{c}E_{p}-E_{p / 2} \\
V\end{array}$ & $\begin{array}{c}\mathrm{i}_{\mathrm{p}} \times 10^{3} \\
\mathrm{~A}\end{array}$ & $\begin{array}{l}\mathrm{W}^{\mathrm{P}} \\
\mathrm{V}\end{array}$ & $\left(\mathrm{dI}_{1} / \mathrm{dt}\right)_{\mathrm{f}} /\left(\mathrm{dI}_{1} / \mathrm{dt}\right)_{b}$ \\
\hline $\begin{array}{c}\mathrm{EE} \\
\mathrm{E}^{0}{ }_{2}>\mathrm{E}^{0}{ }_{1}, \\
\mathrm{n}_{1}=\mathrm{n}_{2}=1\end{array}$ & 1.008 & 0.169 & 2.24 & 0.277 & 1.31 \\
\hline$E n=1$ & 0.943 & 0.163 & 1.16 & 0.243 & 0.765 \\
\hline$E n=2$ & 0.494 & 0.078 & 3.30 & 0.124 & 6.740 \\
\hline $\mathrm{CE} n=1$ & 0.934 & 0.161 & 1.16 & 0.249 & 0.829 \\
\hline
\end{tabular}

$$
\begin{aligned}
& \operatorname{Zn}(I I) b \stackrel{k_{1}}{\rightleftharpoons} \quad \operatorname{Zn}(I I) a \\
& \left(k c=k_{1}+k_{-1}\right)
\end{aligned}
$$

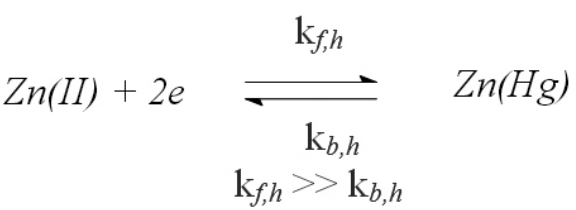

where the subscripts $b$ and $a$ denote to the bulk of the solution (inactive species) and the plane of the closest approaches (active species) respectively. 


\section{REFERENCES}

1. H.L. Jindal, K.Matsuda, R. Tamamushi, J. Electroanal. Chem. 90, 197, (1978).

2. S. Vavricka, J. Kuta, R. Tamamushi, J. Electroanal. Chem. 133, 299, (1982).

3. S. Kang, K. Matsuda, R. Tamamushi, Collect. Czech. Chem. Commun 47, 1433, (1982).

4. W.S. Go, J.J. O'Dea, J. Osteryoung, J. Electroanal. Chem. 255, 21, (1988).

5. A. Lasia, M. Bouderdala, J. Electroanal. Chem. 288, 153, (1990).

6. J. Saba, D. Gugala, J. Nieszporek, D.Sienko, Z. Fekner, Electrochim. Acta, 51, 6165, (2006).

7. N. A. Hampson, R.S. Lathamin: in A.J. Bard (Ed., Encyclopedia of electrochemistry of the elements. Vol I. Marcel Dekker, New Yourk, ch. 4.

8. K.J. Vetter, Electrochemical kinetics. Academic pres, New York. (1976 p. 652

9. V.v. Losev, Modern aspects of electrochemistry. Edited by B. E. Conway and J.O’M Bockris. Butterworths, London. (1972) p.314

10. W. Gorski, J. Lipkowski, J. Electroanal. Chem 123, 157, (1981).

11. L. Janiszewska, Z. Galus, Electrochim. Acta 29, 1419, (1984).

12. N.S. Hush, J. Blackledge, J. Electroanal. Chem 5, 420, (1963).

13. R. Andreu, M. Sluyters-Rehbach, A.G. Remijnse, J.H. Sluyters, J. Electroanal. Chem. 134, 101, (1982)..

14. M. Perez, A. Baars, S.J.M. Zevenhuizen, M. Sluyters-Rehbach, J.H. Sluyters, J. Electroanal. Chem. 397, 87, (1995).

15. I.S. Dunnett, D. Geary, Electrochim. Acta 19, 907, (1974).

16. W.R. Fawcett, A.Lasia, J. Electroanal. Chem 279, 243, (1990).
17. W. Jaenicke, P.H. Schweitzer, Z. Phys. Chem. N.F. 52, 104, (1967).

18. A.S. Amin, Y.M. Issa, J. Pharm. Biomed. Anal. 31, 491, (2003).

19. A.G. Massey, Main group chemistry. Edited by J. Burgess, Ellies Horwood (1990) pp $461-465$.

20. R.M. Rodriguez, E. Brillas, J.A. Garrido, J. Chem. Soc., Faraday Trans I, 83(9), 2813, (1987).

21. R.J. Klingler, J.K. Kochi., J. Phys. Chem 85, 1731, (1981).

22. R.S. Nicholson, I. Shain., Anal. Chem. 36, 706, (1964).

23. A.J. Bard, L. R. Faulkner, Electrochemical methods, Fundamentals and applications, Wiley, New York, 1980.

24. I.C. Imbeaux, J.M. Saveant, J. Electroanal. Chem 44, 169, (1973).

25. I.D. Dobson, N. Taylor, L.R.H. Tipping, Electrochemistry Sensors and Analysis, Elsevier, Amsterdam, pp 61 - 75, 91986).

26. I.S. El-Hallag, M.M. Ghoneim, E. Hammam, Anal. Chim. Acta 414, 173, (2000).

27 Y.I. Moharram, J. Electroanal. Chem 587, 115, (2006).

28. K.B. Oldham, Anal Chem 45, 39, (1973).

29. M. M. Ghoneim, I. S. El-Hallag, J. Braz. Chem. Soc. 21, 7, (2010).

30. A.Blagg, S.W. Carr, G.R. Cooper, I.D. Dobson, J.B. Gill, D.C.Goodal, B.L. Shaw, N.Taylor, T. Bddington, J. Chem. Soc Dalton Trans. 1213, (1985).

31. S.A. EL-daly, I.S. EL-Hallag, E.M. Ebeid, M.M. Ghoneim, Chin J Chem, 27, 241, (2009).

32. M. Goto, K.B. Oldham, Anal. Chem 48, 1671 (1976). 